\title{
Relationship between Adolescents' Perceptions of Their Parents' Behaviours and Youths' Non-Illegal and Minor- Illegal Delinquency in Nairobi Secondary Schools, Kenya
}

\author{
Kariuki, N. Scolastica \\ Daystar University, Kenya \\ *Peter J.O. Aloka \\ Jaramogi Oginga Odinga University of Science \& Technology, Kenya \\ Email: jairopeteraloka@yahoo.com \\ Kinai, Theresia \\ Kenyatta University, Kenya \\ Gatumu, Haniel Nyaga \\ University of Nairobi, Kenya
}

\section{Sr Florentina Ndunge Ndeke}

Catholic University of Eastern Africa, Kenya

Doi:10.5901/mjss.2014.v5n7p390

\section{Abstract}

The study investigated the relationship between adolescents' perceptions of parental behaviours and their involvement in nonillegal and minor-illegal delinquency in selected secondary schools, in Nairobi County of Kenya. The study was informed by Parenting models theory, Social Control Theory and Ego identity versus Role confusion theory. A co relational survey design was employed and the participants comprised 219 females and 191 male students selected by use of stratified and simple random sampling methods. Data was collected using questionnaires and a behaviour checklist. Data was analyzed using parametric correlation statistics. The study revealed that, parental supportiveness was not related to adolescents' non-illegal and minor-illegal delinquent behaviours. That is, the adolescents who perceived excessive parental monitoring comprised the highest percentage of those who were involved in occasional non-illegal (77.6\%) and occasional minor-illegal (51.7\%) delinquent behaviours. The highest percentage of the persistent non-illegal (17.5\%) and persistent minor-illegal (7.7\%) delinquent behaviours were those who perceived excessive parental monitoring. The lowest percentage of the adolescents who were involved in occasional non-illegal (46.2\%) and persistent non-illegal (7.7\%) behaviours were those who perceived low parental monitoring. The results also revealed a significant positive relationship between adolescents' perceptions of parental monitoring and non-illegal, and substance abuse delinquent behaviours. The study recommended psychosocial training for parents to enhance effective parenting.

Keywords: relationship, perceptions, supportiveness, monitoring, adolescents', perceptions, parents, non-illegal, minor- illegal, delinquency, secondary schools.

\section{Introduction}

In the last decade, a lot of antisocial behaviours have been observed in Kenyan secondary schools. The problem behaviours have been of such great concern that Government of Kenya, (2001) presents the Wangai report which examined the causes and remedies to mass indiscipline and unrests among secondary school students. Aloka \& Bujuwoye, (2013) also contend that, behaviour problems among Kenyan secondary school students have been on the rise over the years. For example, in the year 2001, some students used petrol to burn a Kyanguli Boys' Secondary school's dormitory and some 68 students died in the inferno (Kindiki, 2004). Both 2002 and 2005 also witnessed cases of arson in different Kenyan secondary schools by students (Aloka, 2012). In July 2012, over 300 students of two Kenyan 
secondary schools were reported to have boycotted classes and violently protested their school authorities' decision refusing to shift entertainment sessions from daytime to nighttime (Wanjohi, 2012). Kithinji and Kithinji (2005) argue that problem behaviours are related to parents not spending time with their children. Such parents fail in meeting the socialisation needs of their children and hence they develop problem behaviours. Some observations indicate that the role confusion observed among adolescents is linked to parents absconding responsibilities in raising their children (Muindi \& Koro, 2008).

It is generally accepted that parents are the first socializing agents for their children's behaviour. It is common practice for parents to teach their children social rules and roles by explaining, rewarding and punishing them. However, sometimes parents unconsciously socialise the conducts they may not want their children to adapt. As such, parents are often blamed when children engage in antisocial behaviour. Some parents are warm, responsive and child centered in rearing their children. Other parents are rejecting, unresponsive, and essentially uninvolved with their children. On the other hand, some parents are demanding and restrictive on their children while others are permissive and undemanding. The permissive parents tend to allow their children to do as they wish. When a parent is warm and loving the child is likely to want to maintain the parents' approval. To secure the approval some children are likely to avoid any situations that would make them lose the parents' love (Grusec \& Davidov, 2007).

Matherme and Thomas (2001) assert that, family cohesion successfully predicts the frequency of delinquent acts for nontraditional families. They reveal that families that are ridden with conflicts are also likely to fail in meeting their children's needs. Over all the adolescents in such families tend to develop a negative attitude towards one or both of their parents as a result of the conflicts. A negative relationship and a failure to meet the adolescents' needs are likely to make teenagers to ignore the behavioural demands of their parents. On the whole, this unhealthy family climate is likely to lead adolescents' into indulgence in delinquent conducts. Children who grow up in homes ridden with conflict are likely to have greater risk of becoming delinquents.

Siegel and Welch (2009) describe children's conducts that violate social laws as juvenile delinquency. They assert that some of the delinquent behaviours adolescents engage in are criminal, for example violence, stealing, and drug abuse. On the other hand, offences such as disobedience to school rules and truancy are status offenses. Status offenses are non- illegal yet are antisocial for children because they are underage (below 18 years). Sigel \& Welch view such children who engage in illegal acts as needing supervision, support and control for behaviuor shaping. From the preceding discussions, it appears there is an upsurge of antisocial behaviour among adolescent children. The cited incidences of delinquency in schools in the recent years seem to be blamed on parenting. The delinquent behaviours are manifested among high school adolescents as discipline problems (Dishion \& Bullock, 2002). The researcher therefore saw the need to find out the relationship between adolescents' perception of parental behaviours and their involvement in delinquent conducts.

\section{Theoretical Framework and Literature Review}

The theories which informed the study included, parenting models by Baumrind (1991), social control theory by Nye Ivan (1958) and ego identity versus role confusion by Erik Erikson (1980).

\subsection{The parenting models theory}

Baumrind (1968) designed a model on parenting styles and related it to their children's behaviour outcome. She identified responsiveness and demandingness as the parental behaviours that are desirable for child rearing. From the parental responsiveness and demandingness Baumrind identified 3 general parenting styles; authoritarian, authoritative and permissive styles. Based on the theory, it was hypothesised that adolescents' who perceived responsive parenting were likely to be less delinquent than those who perceived less supportiveness. The dimension on demandingness which is also known as control was applied in studying parental monitoring. If the parents exert excessive behaviour monitoring then this is considered as authoritarian control. At the middle of the continuum on demandingness, is authoritative control that involves moderate behaviour monitoring. On the other extreme of the continuum is permissive control that involves little or no monitoring of children (Parke \& Guavain, 2009). According to Baumrind (1968) both authoritarian control and permissive control have negative effects on children's behaviour outcome. Authoritative control on the other hand, has positive effects. Baumrind's parenting dimensions provided the theoretical foundation for examining the parental supportiveness, monitoring and disciplinary measures that constituted some of the depended variables. The theory therefore provided insights on how parental behaviours relate with their children's conduct outcome. Based on the theory, if children perceive their parents as excessively controlling, they are likely to become delinquent. 


\subsection{Social control theory}

The study was also guided by the social control theory which assumes that, children are inherently delinquent and that they need control in order to develop compliance to social law. For example, a failure in social control leads to maladaptive behaviours within an individual, and the failure may not necessarily be real but may be interpreted by the child as so. From this theoretical perspective, the family controls their children's behavior in four ways. First, some parents use direct control that involves punishing children for undesirable behaviours and reward them for compliant ones. The methods used in direct control are checking, rewarding, supervising, putting sanctions, disapproving and excluding. The second approach involves parents training their children and giving explanations of behaviour consequences, and children internalise these trainings and accept the norms and rules as if they were their own. Therefore, children develop both conscience and self-control that guides and guards them against antisocial behaviours, which make them to behave in prosocial ways even when unsupervised. The third control is the indirect control which involves an individual behaving in desirable ways in order to appeal to those who are closest to them. In this case, a strong attachment bond creates an avoidance of undesirable behaviour in anticipation of parental disapproval or deterrence measures. The fourth control is a needs satisfaction control, a combination of two forms of control that are internal and external. Parents create a needs satisfaction control in their children by developing their conscience and meeting their needs. The needs satisfaction makes the children to have an expectation that if they behave in undesirable ways they risk having their needs unmet. The need for conformity develops an innate tendency for fear of rejection by important others and a search for validation.

\subsection{Ego identity versus role confusion}

Erik Erikson (1980) depicts adolescence as a developmental stage involving a crisis in which children are actively seeking appropriate roles, values and vocations. The identity crisis in this stage of development involves an attempt to self-definition which results in either the adolescent finding a role commitment or identity confusion. In the crisis, adolescents seek new roles and statuses. Erikson asserts that adolescents who explore without parental pushing are more likely to find a positive future path and parents who push on an identity for their adolescents may cause their teenagers not to adequately explore their roles and are therefore unlikely to acquire a positive identity. However, parents who fail to provide a clear path for their adolescents to choose from may lead them to excessively explore their world in search for identity. The parents' negative reactions to their children's behaviour as they attempt to find roles and status may yield rebellion and delinquency. Therefore, adolescents who explore without guidance by their parents, those who are rarely monitored and those who are excessively pushed to behave in certain ways risk developing role confusion.

\subsection{Literature review}

Warm and responsive parents are associated with adaptive behaviours such as strong sense of morality (Ladd \& Pettit, 2002). Adolescents who are raised in a warm, loving relationship are likely to be compliant to socially accepted behaviours (Parke \& Gauvain, 2009). Waime (2008) in a descriptive survey examined parent-children relationship in traditional and modern parenting in Nairobi. Waime used a sample of 195 female and 284 male students selected by stratified and simple random sampling. The findings revealed that many parents are not spending time with their children. Some daughters (22\%) and sons $27 \%$ were not sharing meal times with their mothers; some daughters (37\%) and sons $(40 \%)$ indicated that their fathers were uninvolved in helping with their homework. Further, $26 \%$ of daughters and $33 \%$ of sons did not engage in any form of self-disclosure with their mothers while only $41 \%$ of daughters and $51 \%$ of sons involved in self-disclosure with the fathers. This suggests many of the adolescents did not discuss their deep concerns with their parents. The findings showed $10 \%$ of daughters and $16 \%$ of sons did not have their mothers provide psychological needs. On the other hand, $17 \%$ of daughters and $26 \%$ of sons reported that they did not have psychological support from their fathers. Some sons (89\%) and daughters $92 \%$ rated their mothers high on love provision, while $85 \%$ daughters and $80 \%$ of sons rated their fathers as loving. Only a $15 \%$ of adolescents described their parents as discriminating in the provision of support. Mothers (15\%) and $25 \%$ of fathers did not provide educational support for their adolescent children.

Hoffman (2008) studied parents' behaviours and youth delinquency with a sample size of 216 female and 225 male students from Southwestern University. The results confirmed that parental warmth, care and protection (authoritative parenting) is protective to adolescents' substance abuse. However, neglecting parenting was found to be associated with higher rates of alcohol related problems. Another study by Okorodudu (2010) examined parental supportiveness that 
involved a healthy relationship, friendliness, supervision and participation in school work. The study found out that, parental support, an aspect of authoritative parenting was found not significantly related to adolescents' delinquent behaviours. The findings also revealed that parental warmth, care and support do not significantly relate to adolescents' delinquency. The findings provided a pointer to possible findings on perceptions of parental supportiveness and adolescents' delinquency. Jermaine's (2005) study investigated parent-adolescent communication and adolescents' delinquency in Virginia. Data was analyzed using regression analyses, and the study found out that, parent-adolescent communication was related to adolescents' delinquency for non-intact families. In addition, less parent-adolescent attachment and less parent- adolescent communication was related to delinquency for intact families. Jermaine's study provided a basis for better understanding of the influence of parental supportiveness on adolescents' delinquency.

Another important aspect of parenting dimension is control, which refers to the restrictions that parents put to ensure that their adolescent children develop pro-social behaviours. Barber and Harmon (2001) argue that psychological control of children's behaviour involves the use of emotion-directed techniques. Psychologically controlled adolescents are likely to rebel against their parents and the socially imposed rules.

A study involving parenting styles and adolescents' delinquency was conducted among Pittsburgh youth (Hoeve, Dubus, Loeber, Gerris, \& Laan, 2007). The researchers examined parental supervision and adolescents' involvement in delinquent behaviours. The study reported that, low control parenting was significantly linked with adolescents' involvement in moderate and serious persisting delinquency. Other findings were that, a majority of the self reported delinquents were involved in theft and vandalism. The violent adolescents comprised $2.4 \%$ while the serious persisting offenders who were involved in violence offences consisted $20.6 \%$. The serious desisting were $54.0 \%$. Griffin, Botvin, Scheier, Diaz, and Miller (2000) examined parenting and adolescents problem behaviours in New York. The findings revealed that, monitoring (frequency of checking homework) and other parenting behaviours (eating dinner with children) had a strong and inverse relationship to delinquent behaviour in single parent than in two-parent families. Two-parent families constituted $57 \%$ of adolescents respondents, $43 \%$ lived in single-parent families, and $31 \%$ lived in mother only family while $2 \%$ lived with the father only. Moreover, Factor analysis, (on five aggression behaviours) showed a correlation of 0.56 , picking fights 0.80 , hitting with the intention to hurt scored 0.79 and destroying other's property scored 0.70. Item loadings for delinquency factor were 0.80 for shoplifting, 0.78 for stealing for stealing something worth more than $\$ 50$ value or more while throwing rocks scored 0.70 , vandalizing at school scored 0.69 and taking something by force scored 0.69 . In addition, parental monitoring was related to lower delinquency levels and less smoking. Parental monitoring was also associated with less drinking for sons and more drinking for daughters, and over all parental monitoring explained $12 \%$ of variance in smoking and alcohol consumption. Rhucharoenpornpanich, Chamratrithirong, Fongkaew, \& Rosati (2010) examined parenting and adolescent problem behavior among selected Bangkok in India. The bi-variate analysis, ANOVA (F-test) and $X^{2}$ test and the findings revealed that, monitoring was found to protect adolescents from delinquency. For example, parental authoritative control scored the highest mean of 31.5, permissive 2.03 and authoritarian 1.85 on their sons. For daughters, authoritative control scored 3.12, permissive 2.08 and authoritarian 1.82. Further, female adolescents reported higher mean score of parental monitoring (3.16) than sons (2.94) on knowledge of the whereabouts, parental rule and supervision behaviour. Orratai, Aphichat, Fongkaew, Rosati, Miller and Kappa (2010) studied parenting and adolescents' delinquency in Thailand. The findings revealed that, the average score of parental monitoring was higher for daughters than for sons- setting rules $(\rho<.001)$, and knowledge for whereabouts $(\rho<.01)$. Low communication between sons (1.9) and daughters (2.1) out of a maximum score of 4 was observed, that many parents had little communication with their children. Among the adolescents, $69 \%$ of sons and $75 \%$ of daughters had never engaged in delinquent behaviours. Findings also showed more freedom and less supervision of sons lead to more chances of engaging in risky and problematic behaviours.

Anderson and Stavrou, (2000) survey in Dar-es-Salaam, Tanzania investigated the causes of the criminality among youth. The findings revealed that, inadequate parental supervision and inaccessibility to family were linked to adolescents' involvement with deviant peers. Stealing, robbery and mugging were the common types of crime committed by the juvenile youth. Youth violent crimes accounted for $20 \%$ of all arrests. In Kenya, Ndetei (2008) investigated substance abuse using a sample of 1,328 students from 17 public secondary schools. The study found out that beer, wine, spirits, and cigarettes were commonly abused, and that, children as young as eleven years, mainly from educated middle-class families were abusing drugs. Parental absence (mainly for the educated parents who are too busy with careers for their children checking) led to decreased supervising of adolescents. The study reported that, most drug abusing adolescents came from homes where one or both of the parents modeled substance abuse or had lenient attitude to use of alcohol. Therefore, substance abuse was associated with poor monitoring.

The reviewed literature seems to suggest that various forms of parental supportiveness vary in the way they relate to adolescents' delinquency, and as such, there seems to be no consensus on the relationship between parental support 
and adolescents' delinquency. The studies examined varied forms of parental supportiveness and adolescents' delinquency using likert scale and regression analysis. However, the current study investigated the relationship between parental supportiveness and adolescents' delinquent conducts using the youths' perceptions of parental behaviours and self-report measures of delinquency. In addition, the studies on parental monitoring and adolescents' delinquency indicate that the researchers in the area chose to either use adolescents only or adolescents and their parents to investigate the relationship. Most of the studies used adolescents in early to mid adolescence. Some studies seem to have concentrated on control behaviours that involve joint adolescent- parent activities, and as such, a lack of consensus could be emerging from the differences in the parental control variables that are measured. In the current study, the researcher investigated the relationship between adolescents' perceptions of parental monitoring involving control of whereabouts, setting rules and controlling peer association.

In light of the aforementioned, it is clear that adolescents' behaviour problems are a major concern in Kenya. The delinquency problem seems to be blamed on poor parenting. Such problem behaviours have been found to have negative correlation with school engagement and academic achievement (Bryant, Schulenberg, O'Malley, Bachman., \& Johnson 2003). Some investigations on adolescents' problem behaviours in Kenya have been done. For example, Kinai (2002) studied the relationship between parental behaviours towards adolescents and their manifest aggression, and found out that harsh, cruel, neglecting and rejecting parental behaviours correlated with higher manifest aggression mean scores. So far, there is scanty literature on the relationship between parental behaviours and adolescents' delinquent conducts in Kenya.

\subsection{Goals of the study}

The study investigated the relationship between adolescents' perceptions of their parents' behaviours and their non-illegal and minor illegal delinquency.

\subsection{Research Hypotheses}

To assess the relationship between adolescents' perceptions of parental behaviours and adolescents' juvenile delinquency the researcher set the following null hypotheses-:

- There is no significant relationship between adolescents' perceptions of parental supportiveness and their involvement in non-illegal and minor-illegal delinquent behaviour.

- There is no significant relationship between adolescents' perceptions of parental monitoring and their involvement in non-illegal and minor-illegal delinquent behaviours.

\section{Research Methodology}

\subsection{Research design}

The study adopted a correlational survey design. The design allows the researcher to describe different events, experiences, or behaviors and look for links between them_(Shaughnessy, Zechmeister \& Jeanne, 2011). However, the design does not enable researchers to determine causes of behavior. Such a design is useful when the objective is to find out the relationships between variables but does not need to prove causation (Mugenda, 2008 \& Robson, 2002). The design was appropriate because the researcher needed to correlate adolescents' perceptions of parental behaviours and their delinquent behaviours.

\subsection{Population and sample}

In this study the research population was adolescents in Nairobi County Public Secondary Schools. Nairobi has 60 Public Secondary School which had registered for KCSE exam by the year 2010 as shown by the Sampling frame. There were male adolescents in 19 Boys' schools, female adolescents in 20 Girls' schools and both male and female adolescents in 21 Co-educational schools. Using simple random sampling, two schools were selected from each single gender category of schools. In addition, one Co-educational school was selected by simple random sampling. Further, adolescents in one Form 1 and in one Form 3 in each of the sampled schools were randomly selected for schools with more than 1 stream. It was observed that an inclusion of form two adolescents for the study would provide a very close age range since the Form 1 and Form 2 students are very close in age. The Form $4 \mathrm{~s}$ were left out as they were busy preparing for exams. 
The selection of form 1 and 3 students allowed for a good spread cross-section range of adolescents age. According to Gay, (1992) a 10\% of a population constitutes an adequate representative sample of study. As such, 90 students in each of the 5 schools will constitute an adequate sample of 450 adolescents. Out of the target sample of $450,97.7 \%$ participated in the study. However, $6.6 \%$ of the participants' questionnaires were discarded for low completion. As a result a final sample of 410 was registered for the study.

\subsection{Research instruments}

The questionnaire was used to assess adolescents' perceptions of parental behaviours while the behaviour check list was used to measure adolescents' involvement in delinquent behaviours. Self-report measures have high validity with respect to objective measures of delinquent behaviour (Regoli \& Hewitt, 1997). The researcher used Chronbach's alpha to estimate reliability coefficient of the self-report items (54) and behavior checklist items (30) used in the study. Perceived parental support was assessed using 6 items (Section B). The items sought to find out if parents discussed issues with an open and friendly way, whether the adolescents felt their parents met their special needs, provided security, protection and comfort when troubled. Further the adolescents were asked whether they enjoyed joint activities with the parents and if the parents participated in their school activities. The responses were in always, often and rarely form.

Items in Section C assessed perceived parental monitoring. The section comprised items that assessed adolescents' perceptions of parental behaviour monitoring. Adolescents responded to questions on whether their parents sought to know their friends, forbid them to do things they especially enjoyed when they misbehaved, and if parents set clear rules of behaviour. Further, adolescents reported whether the parents were keen to know their where-about and activities. In addition, the teenagers indicated if their parents come to school to check on how they behaved.

The construct validity was ascertained through the use of peers, expert judges and panels. The approach also enhanced content validity (Nachmias \& Nachmias 1987). Criterion validity was also used the correlation finding were assessed for significance by testing the null hypotheses at pre- specified alpha levels. For the instrument used in this research a Chronbach's Alpha reliability coefficient of 0.827 was obtained after taking the average of intercorrelations of the items categories for each variable.

\subsection{Data collection procedures}

In preparation to collect data the researcher obtained permission from Graduate school of Kenyatta University. The researcher also sought a permit from the Ministry of Education, Science and Technology. Further, permission was also sought and granted from the sampled schools and the selected adolescents in secondary schools. Clear instructions were given by the researcher and the students were relaxed by giving a non biasing talk. The Form 1 and 3 students were issued with numbered questionnaires. It took about 30 minutes for the questionnaires to be filled. After completion, the instruments were collected

\subsection{Data Analysis}

The researcher analyzed the relationship between perceived parental behaviours and the adolescents' involvement in the delinquent behaviours. First, contingency tables were run and then correlation coefficients were computed for perceived parental behaviour. Pearson Correlation Coefficient was computed to examine the relationship between parental supportiveness, control, disciplinary techniques, conflicts and the youths' age and adolescents' non-illegal and minor illegal delinquent behaviours. In addition, the correlation between parental alcohol use, and non-illegal and minor illegal delinquent behaviours was computed using Spearman correlation Coefficient. After the researcher coded the responses, the data was entered into the statistical package for social sciences (SPSS) version 21. Results on non-illegal delinquent behaviours were obtained by computing the mean score on adolescents' noncompliance and truancy. On the other hand, adolescents' involvement in minor-illegal delinquency was obtained by computing mean scores for combined violence, substance abuse and stealing. Further, the results on generalised delinquency were obtained by computing combined mean scores for non- illegal and minor illegal delinquent behaviours. The mean scores for non-illegal, minor-illegal and generalised delinquency were ranked according to adolescents involvement as follows; scores of 1-1.45 were considered as never involved ( normative behaviour), 1.46 - 2.45 as occasionally involved and 2.46 - 3 as persistently involved in the delinquent behaviours.

For the independent variables, data on adolescents' perceptions of parental support was summed up for each 
respondent and mean scores on parental supportiveness were computed. A mean scored ranging from 1-1.45 was considered as inadequate, $1.46-2.45$ as moderate and $2.46-3$ as excessive support for the adolescents. On perceived parental behaviour monitoring the scores were summed up for each respondent and mean scores on parental behaviour monitoring were computed. Mean scores that ranged from 1-1.45 were considered to be low, 1.46 - 2.45 (moderate); and (2.46 - 3 (excessive) behaviour monitoring. In addition, adolescents' responses on parental disciplinary techniques (use of harsh words and use of physical punishment) were analysed as rank data which were - 1 (always), 2 (often) and 3 (rarely). Further, the scores on use of harsh word and physical disciplining were summed up and a mean score on punitive disciplining were obtained. The parental punitive disciplining mean scores were categorised as - 2.56- 3 (always). 1.46 - 2.45 (often); 1-1.45 (rare).

The $p$-value set for the test of hypothesis using Pearson correlation coefficient and Spearman correlation coefficient was at $99 \%$ or $95 \%$ level of significance (two -tailed statistical test). The computed $P$-values that were less than $1 \%$ probability level $(P<.01)$ or less than $5 \%$ probability level $(P<.05)$ indicated that the null hypothesis was unlikely to be true. So it was rejected, since there was a correlation between the variables being measured. The rejection of the null hypothesis meant that the alternative hypothesis was adopted since there was significant correlation was found. However, the results that indicated $p$-value greater than $1 \%$ or $5 \%(p>.01)$ or $(p>.05)$ respectively meant that there was no significant correlation between the variables. So the null hypothesis was retained because they could have occurred by chance.

\section{Findings and Discussion}

\subsection{Demographic Characteristics of the Respondents}

The results of adolescents' demographic characteristics on gender, age, and school type were reported. The participants comprised $53.4 \%$ females and $46.6 \%$ male adolescents. Majority of the adolescents (62\%) aged 15-16 years. Some $20.1 \%$ of the adolescents were females and $15.9 \%$ were males in single gender boarding schools. Day school male adolescents comprised $22 \%$ while male comprised $13.2 \%$ of the sample (see Table 1).

\subsection{Adolescents' Perceptions of Parental Supportiveness and their Involvement in Delinquent Behaviours}

The study determined the relationship between adolescents' perceptions of parental supportivess and their involvement in non-illegal and minor-illegal delinquent behaviours. The descriptive and inferential statistical results on parental supportiveness and adolescents' involvement in delinquent behaviours were reported. The participants responded to questions on parental supportivess. The information from descriptive statistics indicated that, adolescents who perceived inadequate parental support comprised the highest percentage (15.4\%) of those who never got involved in delinquent behaviours. The lowest percentage (7.5\%) of adolescents who never got engaged in delinquent behaviours perceived excessive parental support. The adolescents who perceived moderate support comprised the highest percentage (77.1\%) of those who got involved in occasional non-illegal delinquent behaviours. Those who perceived excessive parental support comprised the lowest percentage (74.9\%) of adolescents who were involved in the occasional non-illegal behaviours. On the other hand, the adolescents who perceived excessive parental support comprised highest percentage (17.6\%) of adolescents who were involved in persistent non-illegal delinquent behaviours. The lowest percentage (7.7\%) of those who got involved in the persistent non-illegal behaviours perceived inadequate parental support. Adolescents who perceived inadequate parental support comprised the highest percentage (61.5\%) of the adolescents who got involved in occasional minor-illegal behaviours. The lowest percentage (47.7\%) of those who were involved in the occasional minor-illegal behaviours perceived excessive parental support(Table 1). 
Table 1: Perceived Parental Supportivess and Adolescents' Delinquent Behaviours

\begin{tabular}{|c|c|c|c|c|c|c|c|c|}
\hline \multirow{2}{*}{ Parental Supportiveness } & \multicolumn{7}{|c|}{ Adolescents Involved in Delinquent Behaviours } \\
\cline { 2 - 9 } & Never & Occasional & Persistent & Total & Never & Occasional & Persistent & Total \\
\cline { 2 - 9 } & 21 & 209 & 49 & 279 & 143 & 133 & 3 & 279 \\
\hline \multirow{2}{*}{ Excessive Support } & $7.5 \%$ & $74.9 \%$ & $17.6 \%$ & $100 \%$ & $51.3 \%$ & $47.7 \%$ & $1.1 \%$ & $100 \%$ \\
\hline \multirow{2}{*}{ Moderate Support } & 9 & 91 & 18 & 118 & 56 & 61 & 1 & 118 \\
\cline { 2 - 9 } & $7.6 \%$ & $77.1 \%$ & $15.3 \%$ & $100 \%$ & $47.5 \%$ & $51.7 \%$ & $.8 \%$ & $100 \%$ \\
\hline \multirow{2}{*}{ Inadequate. Support } & 2 & 10 & 1 & 13 & 5 & 8 & 0 & 13 \\
\cline { 2 - 9 } & $15.4 \%$ & $76.9 \%$ & $7.7 \%$ & $100 \%$ & $38.5 \%$ & $61.5 \%$ & $.0 \%$ & $100 \%$ \\
\hline \multirow{2}{*}{ Total } & 32 & 310 & 68 & 410 & 204 & 202 & 4 & 410 \\
\cline { 2 - 9 } & $7.8 \%$ & $75.6 \%$ & $16.6 \%$ & $100 \%$ & $49.8 \%$ & $49.3 \%$ & $1.0 \%$ & $100 \%$ \\
\hline
\end{tabular}

From the information presented in Table 1, the adolescents who perceived excessive parental support (1.1\%) comprised the highest percentage of those who were involved in persistent minor-illegal delinquent behaviours. Those who perceived inadequate parental support never got involved in the persistent minor-illegal behaviours. The results on perceived parental supportiveness seem to have no distinct pattern in relation to adolescents' involvement in delinquent behaviours.

To determine whether or not there was a stastistically significant relationship between parental supportiveness and adolescents' involvement in non-illegal and non-illegal delinquent behaviours, a null hypothesis was tested.

\section{$H_{01}$ : There is no significant relationship between adolescents' perceptions of parental supportiveness and their} involvement in non-illegal and minor-illegal delinquent behaviours.

To achieve this, the Pearson Product Moment Correlation at $\alpha=.01$ was computed to test the relationship between adolescents' perceptions of parental supportiveness and non-illegal and minor-illegal delinquent behaviours. The results show that the correlation between parental supportivess and adolescents' non-illegal delinquent behaviours is $r(.23)=$ $.640, p>.01$. On the other hand, the correlation between perceived parental supportiveness and adolescents' minorillegal behaviours is $r(.000),=1, p>.01$. The results indicate that there was no significant relationship between perceptions of parental supportiveness and adolescents' non-illegal and minor illegal delinquent behaviours. Therefore, the null hypothesis $\left(\mathrm{H}_{01}\right)$ which stated that, there is no significant relationship between adolescents' perceptions of parental supportiveness and their involvement in non-illegal and minor-illegal delinquent behaviours, was thus retained at $p>.01$. The results imply that parental supportiveness does not significantly associate with adolescents' involvement in non-illegal and minor illegal and generalized delinquent behaviours (Table 2).

Table 2: Correlation between Perceived Parental Supportiveness and adolescents' Delinquent Behaviours

\begin{tabular}{|c|c|c|c|c|c|}
\hline & & Non-illegal & Minor-illegal & MDel & Parental Support \\
\hline \multirow{3}{*}{ Non-illegal } & Pearson Correlation & 1 & $.555^{* *}$ & $.914^{* *}$ & .023 \\
\hline & Sig. (2-tailed) & & .000 & .000 & .640 \\
\hline & $\mathrm{N}$ & 410 & 410 & 410 & 410 \\
\hline \multirow{3}{*}{ Minor-illegal } & Pearson Correlation & $.555^{\star \star}$ & 1 & $.845^{* *}$ & .000 \\
\hline & Sig. (2-tailed) & .000 & & .000 & 1.000 \\
\hline & $\mathrm{N}$ & 410 & 410 & 410 & 410 \\
\hline \multirow{3}{*}{ MDel } & Pearson Correlation & $.914^{\star *}$ & $.845^{* *}$ & 1 & .015 \\
\hline & Sig. (2-tailed) & .000 & .000 & & .764 \\
\hline & $\mathrm{N}$ & 410 & 410 & 410 & 410 \\
\hline \multirow{3}{*}{ Parental Support } & Pearson Correlation & .023 & .000 & .015 & 1 \\
\hline & Sig. (2-tailed) & .640 & 1.000 & .764 & \\
\hline & $\mathrm{N}$ & 410 & 410 & 410 & 410 \\
\hline
\end{tabular}

These findings are consistent with Nye's (1958) social control theory which exerts that,individuals will behave in expected ways to have their needs met. As such supportiveness may not relate with delinquency because all adolescents 
continuously seek to have their emotional, physical and social needs met. However, their emotional and social needs are more directed to the peers than the parents. It is observed that the current study findings does not concur with Kinai's (2002) and Gutte's (2007) studies which found that inadequate support is related to adolescents' manifest aggression and problem behaviours respectively. Machteld, Eichelsheim, Van der Laan, Smeenk, \& Jan (2009) describe support as representing a range of positive and negative behavioral aspects such as acceptance, affection, love, support, warmth, responsiveness, sensitivity, communication and intimacy, but also hostility, neglect, and rejection. Wittenborn (2002) found that, supportiveness which involves aspects of authoritative parenting was inversely related to delinquency. The researchers found out that the strongest mean effect sizes were found for negative aspects of support such as neglect, hostility and rejection. In the current research aspects of warmth, acceptance and involvement were examined for relationship with adolescents' involvement in delinquent behaviours. The differences in the variables examined can possibly explain the divergence in findings. In addition, the dependent variables under study were also different.

\subsection{Adolescents' Perceptions of Parental Monitoring and their Involvement in Delinquent Behaviours}

The study examined adolescents' perceptions of parental monitoring and their involvement in non-illegal and minor-illegal delinquent. The participants responded to questions on parental monitoring. The findings from descriptive statistics indicate that, $69.8 \%$ of the adolescents received excess behaviour monitoring, $20.1 \%$ perceived moderate parental behaviour monitoring while $3.2 \%$ perceived low parental behaviour checking. The adolescents who perceived low behaviour monitoring comprised the highest percentage of those who were never involved in non-illegal (46.2\%) and minor-illegal (76.9\%) delinquent behaviours. Those who perceived excessive behaviour monitoring comprised the lowest percentage of the adolescents who never got involved in non-illegal (4.9\%) and those who never got involved in minorillegal (47.6\%) delinquent behaviours. The adolescents who perceived excessive parental behaviour monitoring comprised the highest percentage of those who got involved in occasional non-illegal (77.6\%), and occasional minor illegal (51.7\%).

The adolescents who perceived excessive parental behaviour monitoring also comprised the highest percentage of those who got involved persistent non-illegal (17.5\%) and persistent minor-illegal (7.7\%) delinquent behaviours. The lowest percentage of the adolescents who were involved in occasional non-illegal (46.2\%) and persistent non-illegal (7.7\%) behaviours perceived low behaviour monitoring. In addition, the lowest percentage of the adolescents who were involved in occasional minor-illegal (46.8\%) behaviours perceived moderate behaviour monitoring and the lowest percentage who got involved in minor illegal (.7\%) behaviours perceived excessive behavior monitoring (Table 3).

Table 3: Perceived behaviour Monitoring and Adolescents' Delinquent behaviours

\begin{tabular}{|c|c|c|c|c|c|c|c|c|}
\hline \multirow{3}{*}{$\begin{array}{l}\text { Behaviour } \\
\text { Monitoring }\end{array}$} & \multicolumn{8}{|c|}{ Adolescents involved in Delinquent Behaviours } \\
\hline & \multicolumn{3}{|c|}{ Non-illegal } & \multirow{2}{*}{ Total } & \multicolumn{3}{|c|}{ Minor illegal } & \multirow{2}{*}{ Total } \\
\hline & Never & Occasional & Persistent & & Never & occasional & persistent & \\
\hline \multirow{2}{*}{$\begin{array}{l}\text { Excess } \\
\text { Control }\end{array}$} & 14 & 222 & 50 & 286 & 136 & 148 & 2 & 286 \\
\hline & $4.9 \%$ & $77.6 \%$ & $17.5 \%$ & $100 \%$ & $47.6 \%$ & $51.7 \%$ & $.7 \%$ & $100 \%$ \\
\hline \multirow{2}{*}{$\begin{array}{c}\text { Moderate } \\
\text { Control }\end{array}$} & 12 & 82 & 17 & 111 & 58 & 52 & 1 & 111 \\
\hline & $10.8 \%$ & $73.9 \%$ & $15.3 \%$ & $100 \%$ & $52.3 \%$ & $46.8 \%$ & $.9 \%$ & $100 \%$ \\
\hline \multirow{2}{*}{$\begin{array}{c}\text { Low } \\
\text { Control }\end{array}$} & 6 & 6 & 1 & 13 & 10 & 2 & 1 & 13 \\
\hline & $46.2 \%$ & $46.2 \%$ & $7.7 \%$ & $100 \%$ & $76.9 \%$ & $15.4 \%$ & $7.7 \%$ & $100 \%$ \\
\hline \multirow{2}{*}{ Total } & 32 & 310 & 68 & 410 & 204 & 202 & 4 & 410 \\
\hline & $7.8 \%$ & $75.6 \%$ & $16.6 \%$ & $100 \%$ & $49.8 \%$ & $49.3 \%$ & $1.0 \%$ & $100 \%$ \\
\hline
\end{tabular}

To determine whether or not there was a statistically significant relationship between adolescents' perceptions of parental monitoring and their involvement in delinquent behaviours, the Pearson Product Moment Correlation coefficient was used to test a null hypothesis. The null hypothesis was stated as follows-:

$H_{02}$ : There is no significant relationship between adolescents' perceptions of parental behaviour monitoring and their involvement in non-illegal and minor-illegal delinquent behaviours

The correlation test results revealed that, adolescents' perceptions of parental behaviour monitoring and their non-illegal delinquent behaviours was $r\left(.147^{\star \star}\right)=.003, p<.01$. The results indicate that adolescents' perceptions of parental monitoring were significantly positively related to their involvement in non-illegal delinquent behaviours (Table 4). 
Table 4: Correlation between Perceived Parental Monitoring and Adolescents' Delinquent Behaviours

\begin{tabular}{|c|c|c|c|c|c|}
\hline & & Non-illegal & Minor-illegal & Generalised Delinquency & Parental control \\
\hline \multirow{3}{*}{ Non- illegal } & Pearson Correlation & 1 & $.555^{* *}$ & $.914^{* *}$ & $.147^{* *}$ \\
\hline & Sig. (2-tailed) & & .000 & .000 & .003 \\
\hline & $\mathrm{N}$ & 410 & 410 & 410 & 410 \\
\hline \multirow{3}{*}{ minor illegal } & Pearson Correlation & $.555^{* \star}$ & 1 & $.845^{* *}$ & .087 \\
\hline & Sig. (2-tailed) & .000 & & .000 & .077 \\
\hline & $\mathrm{N}$ & 410 & 410 & 410 & 410 \\
\hline \multirow{4}{*}{ Generalised Del } & Pearson Correlation & $.914^{* *}$ & $.845^{*+}$ & 1 & $.137^{\text {** }}$ \\
\hline & Sig. (2-tailed) & .000 & .000 & & .006 \\
\hline & $\mathrm{N}$ & 410 & 410 & 410 & 410 \\
\hline & \multicolumn{5}{|c|}{${ }^{* \star}$. Correlation is significant at the 0.01 level (2-tailed). } \\
\hline
\end{tabular}

The correlation between adolescents' perceptions of parental behaviour monitoring and their minor-illegal delinquent behaviours was $r(.087)=.077, p>.01$. Further, the correlation between adolescents' perceptions of parental monitoring and generalised delinquency was $r\left(.137^{* *}\right)=.006, p<.01$. The results revealed that adolescents' perceptions of parental monitoring are not related to their involvement in minor-illegal delinquent behaviours. At $p<0.1$, the null hypothesis was rejected and the alternative hypothesis was adopted for adolescents' perceptions of parental behaviour monitoring and adolescents' non-illegal and generalised delinquency. This indicates that perceptions of parental behaviour monitoring are significantly positively associated with adolescents' involvement in non-illegal delinquent behaviours and higher involvement in generalised delinquency.

The findings imply that parents' behaviour monitoring is linked to adolescents' non-illegal delinquent behaviours and substance abuse. It is also possible that adolescents' violence and stealing are related to other factors that are beyond the current study's scope. Parents influenced their children's morality; teenagers understand and accept that their parents may regulate their moral behaviour (Parke \& Gauvain, 2009). However, they do not agree that parents have a right to regulate personal matters such as appearance and friendship choices; as such parent-adolescents' conflicts over such matters increase with adolescents age (Smetana, 2006). These views explain why parental monitoring is related to non-illegal and substance abuse delinquent behaviours. The adolescents whose parents excessively monitor their friendships, set strict rules, check their whereabouts and behaviours are likely to experience frustrations. As result, it is likely that they can resist control over personal matters. Such resistance can be manifested in involvement in delinquency.

It can be argued that high level of monitoring can be frustrating for adolescents. As a result increased monitoring could have led to more adolescents being involved in the delinquent behaviours. According to Parke and Gauvain, (2009) adolescence stage is a self control phase. During the phase the teenagers gain ability to comply with caregiver's expectations in the absence of external reminders; they can remember rules and routines. At adolescence many children are able to strategise and direct their behaviours. However, some delay in development of self control can lead to a less strong sense of self control that manifests itself in antisocial behaviours. It is thus not surprising that increased perceptions of parental monitoring positively related to adolescents' involvement in non-illegal and substance abuse behaviours. In the current study, parental behaviour monitoring was adult oriented as is the case with authoritarian control. Researchers tend to distinguish between authoritative control and authoritarian control (Baumrind 1968). Authoritarian control refers to adult oriented coercive, restrictive and firm discipline techniques. The control is related to negative behaviour outcome. The authoritarian control emphasizes the negative aspects of strict control that does not involve collaboration with the child. The current study findings show that parental behaviour monitoring is related to adolescents' non-illegal and substance abuse delinquent behaviours. The findings do not concur with findings that suggest that parental authoritarian control is beneficial for children living in urban communities (Laventhal \& BrooksGunn, 2004). However, the divergent findings differ in the age of the children involved in the studies. The current study findings does not concur with a study conducted by Orratai et al., (2010) who found out that more freedom and less supervision of sons lead to higher chances of engaging in risky behaviours. Further, Ang and Goh (2006) found that authoritarian control had positive effects on adolescents' behaviours. The divergent findings could probably be because the findings were based on Asian rural adolescents. It could be that that the Nairobi (urban) adolescent population is more aware of the need for autonomy and there is greater societal value for authoritative control. This could result to a general feeling among adolescents that behaviour monitoring is over bearing. As a result the adolescents who are directly monitored may have rebelled and involved in non-illegal and substance abuse delinquent behaviours. 
However, the current findings concur with those of a study conducted in New York by Griffin, et al., (2000) which reported that, high levels of monitoring led to adolescents' involvement in delinquent behaviours. Another study conducted among the Dutch with adolescents of mean age of 13, their parents and the teenagers' best friend. Keijsers et. al, (2011) study also revealed that, prohibitions of friendships led to increased contacts with delinquent peers. In addition, adolescents in Ethiopia indicated that over controlling follow-up by parents influenced them into involving in problem behaviors (Gutte, 2007). Moreover, the current study findings concurs with Hoffman (2008) which revealed that, fathers' authoritarian control related to higher use of alcohol. There seems to be no agreement on the reviewed studies on whether authoritarian control is negatively related to delinquency or positively related. Most of the studies suggest that authoritarian control is positively linked to adolescents' involvement in delinquency. The current study findings on perceptions of excessive parental behaviour monitoring are positively related to adolescents' non illegal and substance abuse delinquent behaviours. However, the behaviour monitoring is not related to violence and stealing behaviours. The findings on parental monitoring and adolescents' delinquency that excessive behaviour monitoring should be avoided as it relates to adolescents' non-illegal and substance abuse delinquent behaviours.

\section{Concluding Remarks}

The study investigated the relationship between adolescents' perceptions of parental support, monitoring and adolescents' involvement in delinquent behaviours. The delinquent behaviours under investigation were non-illegal (noncompliance to school rules and truancy) and minor-illegal (violence, substance abuse and stealing) behaviours among selected secondary school students in Nairobi County of Kenya. The results of the study were that, there was no statistically significant relationship between perceptions of parental supportiveness and adolescents' non-illegal (noncompliance and truancy) and minor-illegal (violence, substance abuse and stealing) delinquent behaviours. Moreover, adolescents' perceptions of parental behaviour monitoring and their non-illegal delinquent behaviours and generalised delinquency were significantly positively related. It has been found that there is significant adolescents' involvement in noncompliance, truancy, violence, substance abuse and stealing behaviours.

However, one of the limitations of the study was the use of adolescents' self-report measures to gather data. Adolescents' responses about their parents tend to overemphasise the negative aspects. The over-reporting is an attempt by adolescents to portray themselves as unique and independent (Noller \& Callan, 1988). To make up for this limitation, it is recommended that adolescents' self- report measures are used to gather data on less serious delinquent behaviours (Babinske, Hartsough, \& Lambert, 2001). In response to the observations the researcher ensured that the delinquent behaviours that were assessed did not include serious delinquent behaviours.

Teachers and school managers therefore need to increase surveillance on adolescents' behaviours to curb adolescents' involvement in delinquent behaviours. The findings revealed that adolescents' perceptions of some parental behaviours have significant relationship with their involvement in non-illegal, minor-illegal and generalised delinquency. As such, there is need for a multi-faceted approach to adolescents' behaviour management in schools, counseling for children who hold perceptions that their parents use excessive monitoring, punitive discipline, have conflicts and abuse alcohol. Parents should provide support for their children without fear of risking their children to the non-illegal and minorillegal delinquency. The recommendation is based on the findings that perceived supportiveness is not significantly related to the delinquent behaviours that were investigated. The findings revealed that, adolescents' perceptions of some parental behaviours have significant relationship with their involvement in non-illegal, minor-illegal and generalised delinquency. As such, there is need for a multi-faceted approach to adolescents' behaviour management in schools, counseling for children who hold perceptions that their parents use excessive monitoring, punitive discipline, have conflicts and abuse alcohol.

\section{References}

Aloka, P. J. O., \& Bujuwoye, O. (2013). Gender differences in decisions on student disciplinary behaviours by disciplinary panels of selected Kenyan secondary schools. African journals online, 5252-5271

Aloka, P.J.O. (2012). Group polarization in decision making: a study of selected Kenyan secondary school disciplinary panels in Rongo district of Kenya. Published PhD thesis, Faculty of Education, University of the Western Cape, South Africa.

Wanjohi G. (2012). 300 Students From Two Schools in Nyandarua Go On Strike. The Star Newspaper Editorial, 18 th July, 2012.

Kindiki, J. N. 2004). School effectiveness in slum contexts: The case of Nairobi, Kenya. Unpublished PhD. Thesis. University of Birmingham, UK.

Kithinji, C. \& Kithinji, T. (2005). The family: A Kenyan Christian couples perspective. Nairobi: Daystar University.

Muindi, B., \& Koro, J. N. (2008, July 27). School Unrest. Daily Nation pp 22. 
Grusec, J. E . \& Davidov, M (2007). Socialization in the family: The role of parents. In J .E Grusec \& P. Histings (Eds.). Handbook of Socialization (284-398). New Yolk: Guilford Press.

Matherne, M., \& Thomas, A. (1997). Delinquency during the transition to early adulthood: Family and Parenting Predictions from Early Adolescence. Journal of Family Health, 32, 61 -81.

Siegel, L., \& Welsh, C. B (2009). Juvenile Delinquency: Theory Practice and law 10th ed. Belmont: Wadsworth Publishing.

Dishion, T. J., \& Bullock, B .M. (2002). Parenting and adolescence problem behavior. An ecological analysis of the nurturance process, strategy and achievement cognitions following failure. Journal of Personality and Social Psychology, 36, 451- 462.

Baumrind, D. (1991). Effective parenting during the early adolescent transition. In P .A. Cowan \& E. M Hetherington (Eds.). Advances in family research, 2111-163. Hillsdale, NJ: Erlbaum.

Baumrind, D. (1968). Authoritarian vs. authoritative parental control. Adolescence, 3(11), 255-272.

Nye, I. F. (1958). Family relationships and delinquent behavior. New York: John Wiley \& Sons.

Erikson, E. (1980). Identity and the life cycle (2nd eds). New Yorkk, Norton.

Parke, D. R., \& Guavain, M. (2009). Child psychology: A contemporary View. NY McGraw-Hill.

Ladd, G. W., \& Pettit. S. (2002). Parenting and the development of children's peer relationships. Mahwah, NJ: Lawrence Erlbaum Associates, 269-309.

Waime, W. T. (2008). The conflict between modern and traditional parenting behavioursrs as perceived by students in some selected secondary schools in Nairobi province: Counseling implications Unpublished PhD. Theses. Kenyatta University, Nairobi , Kenya.

Okorodudu, R. \& Omoni, G. E (2005). Child abuse \& parental neglect: A cog in the wheel of development in Nigeria. Delsu Journal of Educational Research and Development, 4(1) 125-135.

Hoffman, M. L. (2008). Parenting and delinquency; Pub Med Central Journal of Studies on Alcohol and Drugs, 70 (2):215-226.

Barber, B. K., \& Harmon, E. L. (2001). Violating the self: Parental psychological control of children and adolescents. In B. K. Barber (Ed.), Intrusive parenting: How psychological control affects children and adolescent (15-52). Washington, DC: American Psychological Association.

Jermaine, H. J. (2005). Examining Family Structure and Processes as Predictors in African-American Adolescent Females. Virginia: Virginia Polytechnic Institute and State University.

Hoeve, M., Blokland, A., Dubus, J. S., Loeber, R., Gerris, J. R., \& Laan, V. (2007). Trajectories of delinquency and parenting behaviours. Journal of Abnormal Psychology 36 (2)223-235).

Griffin, K. W., Botvin, G. J., Scheier, L. W, Diaz, T., \& Miller, N. (2000). Parenting practices as predictors of substance use, delinquency and aggression among urban minority youth: Moderating effects of family structure and gender. Psychology of Addictive Behavioursrs, 14, 174-184.

Rhucharoenpornpanich, O., Chamratrithirong, A., Fongkaew, W., \& Rosati, M. (2010). Parenting and adolescent problem behaviours comparative study of Sons and daughters in Thailand. J Med Assoc Thai Vol. 93(3) 293.

Orratai, R., Aphichat, C., Fongkaew, W., Rosati, M., Miller, B., \& Kappa, P. (2010). Parenting and adolescent problem behavior: A comparative study of sons and daughters in Thailand. Journal of Medicine Association Thailand 93(3): 293-300.

Anderson, C., \& Stavrou, A. (2000). Youth delinquency and the criminal justice system: Safer Cities Programme survey. Dar-es-Salaam, Tanzania: UN-Habitat.

Byrant, L. A., Schulenberg, J. E., O’Malley, P. M., Bachman, J. G., \& Johnson D. L. (2003). How Academic Achievement, Attitudes, and Behaviors Relate to the Course of Substance Use During Adolescence: A 6-Year, Multi-wave National Longitudinal Study. Journal of Research on Adolescence, 13, 361 - 397.

Kinai, K. T. (2002). Relationship between parental behavior toward adolescents and their manifest aggression in Nairobi Secondary schools. Unpublished Ph.D. Thesiss, Kenyatta University, Nairobi, Kenya.

Shaughnessy, J.; Zechmeister, E.; Jeanne, Z. (2011). Research methods in psychology (9th ed.). New York, NY: McGraw Hill.

Robson, C. (2002). Real world research (7th eds.), UK Library of Congress.

Mugenda, G. A. (2008). Social science research: Theory and principles. Nairobi: Kijabe Printing Press.

Gay, L. R. (1992). Educational research: Competence for analysis and application. (4th edition). New Yorkk: Macmillan Publishers.

Regoli, M. R., \& Hewitt, D. J. (1997). Delinquency in Society. City? McGraw-Hill Companies, Inc.

Nachmias C. F. \& Nachmias, D. (1987). Research Methods in the Social Sciences (5 ${ }^{\text {th }}$ ed). New York: St. Martin's Press.

Gutte, K. (2007). Perceptions on student's schools related problems behaviours and methods of their intervention in selected primary schools of Lideta Zone, Addis Ababa. Unpublished M.A Thesis, Daystar University, Nairobi, Kenya.

Machteld, H., Judith S. D., Eichelsheim, I, V., Van der Laan, P. H., Smeenk, W., \& Jan R. M. (2009). The Relationship between Parenting and Delinquency: A Meta-analysis. Journal of Abnormal Child Psychology; 37(6): 749-775.

Wittenborn, M. (2002). The Relations between Parenting Styles and Juvenile Delinquency" (2002). Retrieved from http:// www. opensiuc. lib. siu. edu / uhp.

Smetana, J. G. (2006). Social domain theory: Consistencies and variations in children's moral and social judgments. In M. Killen \& J. G. Smetana (Eds.), Handbook of Moral Development ( 119-154). Mahwah, NJ: Erlbaum.

Laventhal, T., \& Brook-Gunn, J. (2004) Diversity in developmental trajectories across adolescence: Neighbourhood influences. In Lerner R M., Eds. Steinberg L. Handbook of adolescent psychology, 2, 188- 191, Hoboken, NJ: Wiley.

Ang, R. P. \& Goh, D (2006). Authoritarian parenting styles in Asian societies: A cluster analytic investigation. Contemporary Family Therapy; An International Journal, 29(1), 132-151. 